Marquette University

e-Publications@Marquette

Physical Therapy Faculty Research and Publications

Physical Therapy, Department of

$2-1-2013$

\title{
EEG During Pedaling: Evidence for Cortical Control of Locomotor Tasks
}

Sanket G. Jain

Marquette University

Krishnaj Gourab

Marquette University

Sheila M. Schindler-Ivens

Marquette University, sheila.schindler-ivens@marquette.edu

Brian D. Schmit

Marquette University, brian.schmit@marquette.edu

Accepted version. Clinical Neurophysiology, Vol. 124, No. 2 (February 2013): 379-390. DOI. (C) 2013 Elsevier. Used with permission. 


\title{
EEG During Pedaling: Evidence for Cortical Control of Locomotor Tasks
}

\author{
Sanket Jain \\ Department of Biomedical Engineering, Marquette University, \\ Milwaukee, WI \\ Krishnaj Gourab \\ Department of Biomedical Engineering, Marquette University, \\ Milwaukee, WI \\ Sheila Schindler-Ivens \\ Department of Physical Therapy, Marquette University, \\ Milwaukee, WI \\ Brian D. Schmit \\ Department of Biomedical Engineering, Marquette University, \\ Milwaukee, WI
}

\begin{abstract}
Objective: This study characterized the brain electrical activity during pedaling, a locomotor-like task, in humans. We postulated that phasic brain activity would be associated with active pedaling, consistent with a cortical role in locomotor tasks.
\end{abstract}

Methods: Sixty four channels of electroencephalogram (EEG) and 10 channels of electromyogram (EMG) data were recorded from 10 neurologically-intact volunteers while they performed active and passive (no 
NOT THE PUBLISHED VERSION; this is the author's final, peer-reviewed manuscript. The published version may be accessed by following the link in the citation at the bottom of the page.

effort) pedaling on a custom-designed stationary bicycle. Ensemble averaged waveforms, 2 dimensional topographic maps and amplitude of the $\beta$ (13-35 $\mathrm{Hz}$ ) frequency band were analyzed and compared between active and passive trials.

Results: The peak-to-peak amplitude (peak positive-peak negative) of the EEG waveform recorded at the $\mathrm{Cz}$ electrode was higher in the passive than the active trials $(p<0.01) . \beta$-band oscillations in electrodes overlying the leg representation area of the cortex were significantly desynchronized during active compared to the passive pedaling $(p<0.01)$. A significant negative correlation was observed between the average EEG waveform for active trials and the composite EMG (summated EMG from both limbs for each muscle) of the rectus femoris $(r=-0.77, p<0.01)$ the medial hamstrings $(r=-0.85, p$ $<0.01)$ and the tibialis anterior $(r=-0.70, p<0.01)$ muscles.

Conclusions: These results demonstrated that substantial sensorimotor processing occurs in the brain during pedaling in humans. Further, cortical activity seemed to be greatest during recruitment of the muscles critical for transitioning the legs from flexion to extension and vice versa.

Significance: This is the first study demonstrating the feasibility of EEG recording during pedaling, and owing to similarities between pedaling and bipedal walking, may provide valuable insight into brain activity during locomotion in humans.

Keywords: Electroencephalography, Pedaling, Brain activity

\section{Introduction}

In humans, the cerebral cortex may play an important role in the control of locomotor function. The role of the cortex may be particularly strong in humans since a unique characteristic of human locomotion, in comparison to other primates, is 'habitual bipedalism with the trunk and head in an erect posture' (reviewed in (Schmitt, 2003)). This type of locomotion has provided humans with a distinct evolutionary advantage over other animals by freeing the upper limbs during locomotion, and significantly decreasing the energy cost of walking (Sockol et al., 2007). However, it has also made the task of walking more complex and possibly more dependent on corticospinal function for humans, compared to lower animals (reviewed in (Nielsen, 2003)). Consequently, in contrast to lower animals (rats, (Little et al., 1988) cats, (Rossignol et al., 2004) rabbits (Lyalka et al., 2005)), and non human primates (Courtine et al., 2005; Babu and Namasivayam, 2008), disruption of supraspinal control, as in stroke (Kelly-Hayes et

Clinical Neurophysiology, Vol 124, No. 2 (February 2013): pg. 379-390. DOI. This article is (C) Elsevier and permission has been granted for this version to appear in e-Publications@Marquette. Elsevier does not grant permission for this article to be further copied/distributed or hosted elsewhere without the express permission from Elsevier. 
al., 2003) or spinal cord injury (Dobkin et al., 2007), more severely impairs locomotion in humans (reviewed in (Rossignol, 2000)). Thus, characterization of the cortical contribution to locomotor control in humans is important to understanding the pathophysiology of impaired locomotion after an injury to the central nervous system.

Assessing the cortical contribution to locomotor control in humans is challenging due to difficulties in quantifying brain activity during walking. Walking generates head movement and requires the subject to be erect and moving in space, with minimal constraints. In order to circumvent these problems, brain activity has been recorded during conditions that differ from actual walking. Approaches have included recording brain activity immediately after walking (Fukuyama et al., 1997), during imagined walking (Deutschlander et al., 2009; Bakker et al., 2008; Iseki et al., 2008; Wagner et al., 2008), during movement of a single lower extremity joint (Dobkin et al., 2004; Sahyoun et al., 2004; Ciccarelli et al., 2005) and during pedaling a stationary bicycle (Mehta et al., 2009; Christensen et al., 2000). Pedaling was used in the current study because it involves actual movement of the legs, which generates sensory feedback, and the reciprocal, cyclical nature of the task is similar to walking.

Previous measurements of brain activity during pedaling have been limited to techniques that are dependent on hemodynamic/metabolic responses, which have restricted the temporal resolution of the data. For example, brain activity has been measured during pedaling using positron emission tomography (PET) (Christensen et al., 2000) and functional magnetic resonance imaging (fMRI) (Mehta et al., 2009), both of which indicate that primary cortical structures are active during pedaling. Since both fMRI and PET are based on hemodynamic/metabolic responses, temporal resolution necessary to ascertain the timing of the brain activity relative to the pedaling cycle is still unknown, as the pedaling cycle is shorter than the hemodynamic response function. Consequently, the use of electroencephalography (EEG) to monitor cortical activity during pedaling is appealing, since EEG is noninvasive and has the capability of high time resolution.

In order to characterize cortical activity during a locomotor-like task, high density (64 channels) EEG measurements were made while

Clinical Neurophysiology, Vol 124, No. 2 (February 2013): pg. 379-390. DOI. This article is (C) Elsevier and permission has been granted for this version to appear in e-Publications@Marquette. Elsevier does not grant permission for this article to be further copied/distributed or hosted elsewhere without the express permission from Elsevier. 
ten young healthy adults pedaled a stationary bicycle. We hypothesized that EEG would demonstrate brain activation over anatomically appropriate scalp regions, i.e. over the expected leg representation area of the sensorimotor cortex, with different patterns of activation during active vs. passive pedaling. Further, a correlation between the EEG activity over these regions of the brain and activity of the leg muscles was expected.

\section{Methods}

\subsection{Study participants}

Ten young, healthy, neurologically intact individuals who were comfortable pedaling for half an hour participated in this study (age 22-32 years, median 26 years). The study protocol was approved by the Institutional Review Board of Marquette University, Milwaukee, Wisconsin. Written informed consent was obtained from all subjects prior to participation in the study.

\subsection{Pedaling device}

The pedaling device and acquisition of crank position data has been described previously (Schindler-Ivens et al., 2008). Briefly, a custom-designed stationary bicycle with a rigid, reclined backboard was used as the pedaling device (Fig. 1). The backboard supported the subject's head and trunk during pedaling, thus reducing movement and neck EMG artifacts in the EEG recordings. An optical encoder (BEI Technologies Inc., Goleta, CA) coupled to the crankshaft via a chain and sprocket assembly was used for digitizing the angular position of the pedals. The digital signal from the optical encoder was converted to an analog signal using a digital to analog converter before sampling by the main data acquisition computer.

Clinical Neurophysiology, Vol 124, No. 2 (February 2013): pg. 379-390. DOI. This article is @ Elsevier and permission has been granted for this version to appear in e-Publications@Marquette. Elsevier does not grant permission for this article to be further copied/distributed or hosted elsewhere without the express permission from Elsevier. 

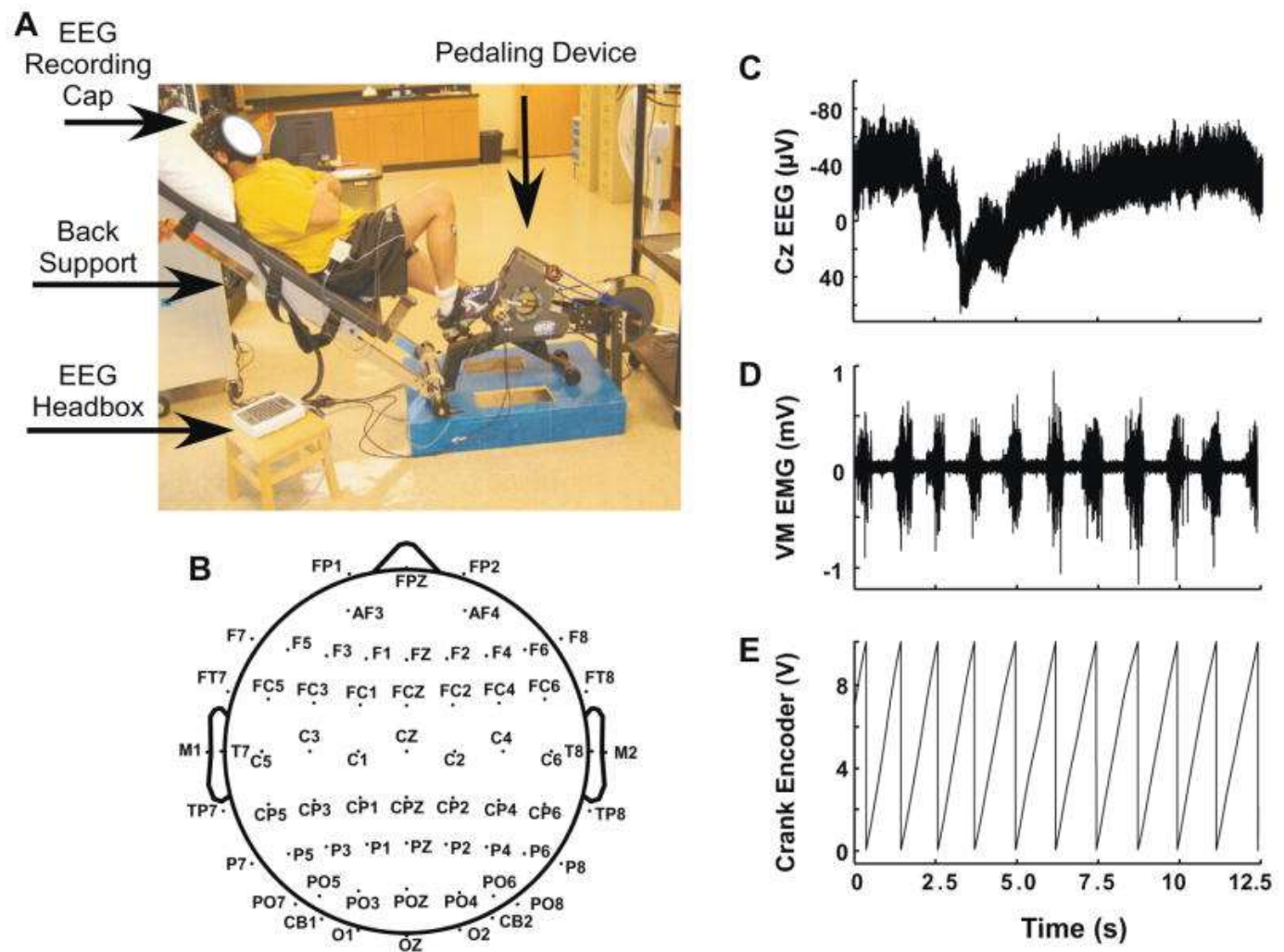

Fig. 1. (A) Experimental setup: the subject is seated in reclined position in a customdesigned pedaling apparatus with the right leg in the TDC position. (B) Schematic showing the position of the 64 electrodes of the electrode cap (Compumedics Neuroscan, El Paso TX). Note that some electrodes are shown outside the head diagram to indicate their inferior position with respect to the other electrodes. (C) Raw EEG data from one subject recorded at the $\mathrm{Cz}$ electrode. This example specifically demonstrates a "worst case" scenario in terms of the drift in the baseline of the signal (note the long timescale). (D) Raw EMG data from one subject recorded at right MH muscle. EMG bursts were typically observed with each pedaling cycle. (E) Voltage data recorded from crank encoder representing crank angle during pedaling. The encoder signal was reset at TDC for the right leg. Figures c-e illustrate raw data for $\sim 11$ pedaling cycles.

\subsection{EEG and EMG recording systems}

The QuikCap electrode cap (Compumedics Neuroscan, El Paso, TX) was used for EEG electrode placement. The stretchable electrode cap contained 64 sintered $\mathrm{Ag}-\mathrm{AgCl}$ electrodes arranged according to the modified combinatorial system of electrode placement (American Clinical Neurophysiology Society, 2006). The reference electrode was positioned near the vertex between the $\mathrm{Cz}$ and $\mathrm{CPz}$ electrodes and the ground electrode was located over the frontal area of the scalp, between the $\mathrm{Fz}$ and FPz electrodes. The $\mathrm{Ag}-\mathrm{AgCl}$ electrodes were

Clinical Neurophysiology, Vol 124, No. 2 (February 2013): pg. 379-390. DOI. This article is @ Elsevier and permission has been granted for this version to appear in e-Publications@Marquette. Elsevier does not grant permission for this article to be further copied/distributed or hosted elsewhere without the express permission from Elsevier. 
located within small receptacles on the scalp side of the cap, which housed sponge-backed felt discs. The electrodes were connected to the EEG amplifier via a headbox, and the headbox was connected to a high input impedance Synamps ${ }^{2}$ amplifier (Compumedics Neuroscan). Before each recording, disposable sponge discs were inserted into the electrode receptacles and the QuikCap was secured to the subject's head with a chin strap. The sponge discs were hydrated with about 0.2 $\mathrm{ml}$ of a proprietary electrolyte solution (Compumedics Neuroscan) which then expanded to make contact with the scalp. Electrode impedances were decreased by additional incremental hydration and maintained below $10 \mathrm{k} \Omega$. The electrodes were connected to the Synamps ${ }^{2}$ EEG amplifier (Compumedics Neuroscan), which in turn, was connected to a PC for data acquisition.

EMG was recorded bilaterally using bipolar skin electrodes (10 $\mathrm{mm}$ length, $1 \mathrm{~mm}$ width, $1 \mathrm{~cm}$ inter-electrode distance, DelSys, Inc., Boston, MA) from the Soleus (SOL), Vastus Medialis (VM), Tibialis Anterior (TA), Medial Hamstrings (MH) (approximately over the semimembranosus muscle belly) and the Rectus Femoris (RF) muscles. EMG signals were pre-amplified $10 \times$ at the electrode site. Remote differential amplification at $1000 \times$ was done using an EMG amplifier system (DelSys Bagnoli-8 EMG System, DelSys, Inc.) with a common mode rejection ratio of $92 \mathrm{~dB}$ and a frequency bandwidth of 20-450 Hz. This amplifier was connected to a PC via a 16 bit A/D converter (Micro $1401 \mathrm{mk}$ (II), Cambridge Electronic Design, Cambridge, England) for acquiring the EMG signals.

\subsection{Experimental protocol}

Subjects were seated on the cushioned seat of the stationary bicycle, with their back reclined on the rigid backboard. The subject's trunk was snugly strapped to the rigid backboard and the head was placed on a bead-filled pillow for stabilization. Each subject performed active and passive pedaling in a single experimental session. During pedaling, whenever the crank rotated through the top dead center position of the right leg (TDC; right leg completely flexed and left leg completed extended (Raasch and Zajac, 1999), a $10 \mathrm{~V}$ pulse was generated by the optical encoder. This pulse was routed to the EEG and EMG recordings to track the start of every pedaling cycle.

Clinical Neurophysiology, Vol 124, No. 2 (February 2013): pg. 379-390. DOI. This article is (C) Elsevier and permission has been granted for this version to appear in e-Publications@Marquette. Elsevier does not grant permission for this article to be further copied/distributed or hosted elsewhere without the express permission from Elsevier. 
(i) Active pedaling For active trials, subjects were asked to pedal forward at a comfortable speed. The eyes were closed to minimize eye movements and blink artifacts and to prevent any visual feedback of the pedaling speed and leg position. Subjects were instructed to pedal at a slow, comfortable rate. No effort was made to cue or control the speed of pedaling in order to prevent EEG activity due to cognitive processes associated with matching the pedaling speed to a visual or auditory cue. The average pedaling speed across all subjects was 2.1 $\mathrm{s} /$ cycle $( \pm 0.5 \mathrm{~s} / \mathrm{cycle})$. The resistance to pedaling was kept at minimum for all trials and subjects. The total duration of the active pedaling was $20 \mathrm{~min}$. A short break after $10 \mathrm{~min}$ of pedaling was provided, if required.

(ii) Passive pedaling For the passive trials, the subject's feet remained strapped to the pedal of the bicycle while the crank was rotated by one of the investigators, with the subject's eyes closed. The speed of passive pedaling was matched to the average speed of active pedaling for the subject. The subjects were asked to completely relax, and EMG from the leg muscles was monitored to confirm that subjects were not generating muscle activity during pedaling. A single trial of 10 min was recorded.

\subsection{Data acquisition and analysis}

Continuous EEG, EMG and crank position data were recorded during each trial. Continuous EEG data were amplified 2010x, filtered at $0.5 \mathrm{~Hz}$ (high pass) to $500 \mathrm{~Hz}$ (low pass), digitized at $2000 \mathrm{~Hz}$ and recorded on a computer running the Scan 4.3 EEG acquisition/analysis software (Compumedics Neuroscan). Crank position and EMG data were sampled at $1000 \mathrm{~Hz}$, digitized by a 16 bit A/D converter (Micro $1401 \mathrm{mk}$ (II), Cambridge Electronic Design) and acquired on a PC running Spike 2.0 software (Cambridge Electronic Design).

A complete dataset for one subject was defined as containing EEG, EMG and crank position data for both the active and passive trials, with at least 140 EEG cycles in each trial. Nineteen sets of data (from 10 active trials and 9 passive trials) fulfilled this criterion, and further analysis was done on these 19 sets. Active pedaling trials had 208-773 cycles (3 subjects had 208-327 cycles, 7 subjects had 465-

Clinical Neurophysiology, Vol 124, No. 2 (February 2013): pg. 379-390. DOI. This article is (C) Elsevier and permission has been granted for this version to appear in e-Publications@Marquette. Elsevier does not grant permission for this article to be further copied/distributed or hosted elsewhere without the express permission from Elsevier. 
773 cycles) and passive pedaling trials had 142-381 cycles ( 1 subject had 142 cycles, 8 subjects had 288-381 cycles). Data analysis was done using the EDIT 4.3 EEG analysis software (Compumedics Neuroscan), the EEGlab toolbox (Delorme and Makeig, 2004) and custom programs written in MATLAB (The Mathworks, Inc., Natick, MA).

Continuous EEG data (.cnt files) were converted into ASCII (.dat files) format for processing. An event file was generated using the EDIT 4.3 software. Timings of each event (each time the right leg reached the TDC position) were used to segregate continuous EEG data into cycles. Each cycle represented EEG activity during one complete pedaling cycle, starting from the TDC position of the right leg. The TDC right position was thus the beginning of each cycle $(0 \mathrm{~ms}$ and $0^{\circ}$ position).

\subsubsection{Scalp potentials phase-locked with the pedaling cycle In} order to identify the scalp potentials associated with the pedaling cycle, an ensemble average of the potential waveform across all cycles was calculated for each electrode. This ensemble average provided a measure of the potentials that were phase locked to the pedaling cycle in a manner similar to the way in which movement related brain potentials provide measures of the potential signals associated with motor activity. We postulated that potential waveforms might emerge with a frequency near the pedaling frequency, reflecting generalized shifts in cortical potentials associated with the pedaling cycle. These waveforms were expected to be prominent for electrodes that typically overlie sensorimotor cortical regions of the legs (especially $\mathrm{Cz}$ ).

The ensemble average voltage waveforms across pedaling cycles were calculated by averaging across cycles, first correcting for the variability in the pedaling cycle. Because subjects were allowed to pedal at a comfortable speed, the length of each pedaling cycle and therefore, the EEG cycle, varied within each trial. Assuming that EEG activity was time-locked to the cycling phase; EEG cycles from the same trial were resized to the same length before they were ensemble averaged to obtain average potential changes across the averaged pedaling cycle. The following algorithm was implemented for resizing the EEG cycles: the mean cycle length was calculated, and cycles with lengths within $0.3 \mathrm{~s}$ of the mean were selected for further analysis.

Clinical Neurophysiology, Vol 124, No. 2 (February 2013): pg. 379-390. DOI. This article is @ Elsevier and permission has been granted for this version to appear in e-Publications@Marquette. Elsevier does not grant permission for this article to be further copied/distributed or hosted elsewhere without the express permission from Elsevier. 
This was an arbitrary threshold, but it allowed cycles of almost similar lengths to be considered for analysis (Mean: $89.7 \%$ of total cycles recorded; Range: 13/19 > 90\% cycles used, $17 / 19>70 \%$ cycles used). The next step was to resize the selected cycles to one standard length. Three times the length of the longest of the selected cycles was taken as a standard cycle length for the trial, and all cycles were resized to this target length using the resample function in MATLAB. This increase in cycle length was used so that when artifacts caused by the resample function were removed from the ends, a minimal amount of signal was lost. This resulted in the same length for each individual cycle, while preserving the overall signal morphology of each cycle. Distortion of the signal for each cycle was observed for about 50 data points ( $0.3 \%$ of the original length) at the start and end of each cycle. These regions were excluded from further analysis. Ensemble-average waveforms for each trial were calculated using the resized cycles. The linear detrend function in MATLAB was used to correct for slow, baseline shifts in the ensemble averaged waveforms. The averaged waveforms were then re-referenced to the whole head (Lehmann and Skrandies, 1980). These ensemble averaged waveforms for single subject were then resized to an arbitrary length (16384 points). The result was a single waveform for each electrode per condition (active and passive). The same analysis was performed for every subject and the ensemble averaged waveforms were generated with the same length.

The results were visualized for both individual and group data. Group ensemble-averaged waveforms were obtained across subjects, generating separate group average waveforms for the active and the passive trials. For both individual and group data, a global linear interpolation algorithm (Neuroscan, 2003) was implemented to generate 2 dimensional topographic maps at specific phases of the pedaling cycle (at peaks of negative and positive deflections of the composite EEG signal from the $\mathrm{Cz}$ electrode, further described in the results section) in the waveforms. These topographic maps represented the spatial voltage distribution over the scalp at specific time points of the pedaling cycle.

2.5.2. Distributed current source localization Source localization of the group ensemble data for both active and passive tasks was performed using Brainstorm software (Tadel et al., 2011). Within

Clinical Neurophysiology, Vol 124, No. 2 (February 2013): pg. 379-390. DOI. This article is @ Elsevier and permission has been granted for this version to appear in e-Publications@Marquette. Elsevier does not grant permission for this article to be further copied/distributed or hosted elsewhere without the express permission from Elsevier. 
Brainstorm software, a 3-shell sphere forward modeling method was used, with the cortical surface selected as the source. A standard brain anatomy was used. The analysis was conducted on the ensemble averaged data from each of the 64 electrodes. The source localization maps were obtained for active and passive tasks at two primary peaks of the $\mathrm{Cz}$ electrode potential. The average EEG data for each channel, active and passive task, were imported into Brainstorm. A minimum norm estimate (WMNE) algorithm was used to calculate the sources from EEG data. Current source density was mapped across a standardized cortical surface. For display purposes, a threshold was applied to the map at approximately $50 \%$ of the peak dipole moment in order to display only the highest values.

\subsubsection{Decreases in $\beta$ band power ( $\beta$ desynchronization) The} frequency content of the EEG signal was analyzed to compare the center of the $\beta$ band $(20-25 \mathrm{~Hz}$ ) power associated with active and passive pedaling. The center frequencies of the $\beta$ band were used to minimize possible interference from a or $y$ signals. A decrease in band $\beta$ band power (i.e. $\beta$ desynchronization) has previously been associated with cortical sensorimotor tasks (Pfurtscheller, 1981). EEG power was calculated using the EEGlab toolbox (Delorme and Makeig, 2004) for MATLAB. Continuous EEG data from each trial, from each subject, were downsampled to $500 \mathrm{~Hz}$ and the first $500 \mathrm{~s}$ of the data were used for this analysis. Separate topographic maps representing the amplitudes of frequencies between 6 and $35 \mathrm{~Hz}$, in $1 \mathrm{~Hz}$ increments were plotted using the spectopo function in EEG-lab. This function utilizes the pwelch (Welch periodogram) function from MATLAB which divides the continuous time-domain signal into 8 segments using a Hamming window with $50 \%$ overlap to calculate the signal power at each frequency $(6-35 \mathrm{~Hz})$. The average power at each frequency was then calculated across subjects for the active and passive trials. Before averaging, the power at each frequency was normalized to the range (maximum power recorded for that trial across all 64 channels - minimum power recorded for that trial across all 64 channels) for the trial. Subsequently, the topoplot function in EEGlab was used to calculate interpolated 2 dimensional topographic maps showing the power of the specified frequency over different regions of the scalp. We expected the group-average frequency topographic maps to show a greater desynchronization (reduced

Clinical Neurophysiology, Vol 124, No. 2 (February 2013): pg. 379-390. DOI. This article is (C) Elsevier and permission has been granted for this version to appear in e-Publications@Marquette. Elsevier does not grant permission for this article to be further copied/distributed or hosted elsewhere without the express permission from Elsevier. 
amplitude) in the $\beta$ band frequencies for the active as compared to the passive trials, consistent with the $\beta$ desynchronization associated with volitional motor tasks. Further, we expected the maximum desynchronization to localize near the electrodes representing the leg representation area of the motor cortex ( $\mathrm{C} 1, \mathrm{Cz}$ and $\mathrm{C} 2$ electrodes).

\subsubsection{EMG analysis EMG was analyzed using custom MATLAB} programs. Fourth order Butterworth filters at $20-450 \mathrm{~Hz}$ (band pass) and $58-62 \mathrm{~Hz}$ (band stop) were used to filter the EMG signal (filtfilt function in MATLAB). The signals were then rectified and enveloped using a 4th order low pass Butterworth filter at $5 \mathrm{~Hz}$.

Due to the proximity of the locations of the right and left leg representation areas of the sensorimotor cortex, we expected the $\mathrm{Cz}$ electrode to represent the electrical activity from both the left and the right leg representation areas of the cortex. To explore the relation between EEG activity recorded at this electrode and the leg muscle EMG activity, composite EMG waveforms representing activity of the same muscle from both legs were generated. EMGs from the same muscle from the left and right legs were added to yield the bilateral composite EMG waveform for each muscle. The group-averaged rectified, smoothed EMG signals from VM, RF and MH muscles were then cross correlated (xcorr function in MATLAB) to the groupaveraged ensemble EEG (i.e. the slow modulation) from all 64 channels. This analysis was used to identify a possible association between the slow potentials measured in the ensemble EEG signals and the generalized activity of each muscle pair. These cross correlation coefficients (not normalized by autocorrelation values) for every muscle were then interpolated on 2-D topographic maps as described previously.

\subsection{Statistical analysis}

Statistical tests were done for the following measures

i. The peak-to-peak amplitude (maximum positive deflection maximum negative deflection) of the ensemble-averaged EEG voltage waveform at the Cz electrode (Jahanshahi et al., 1995) for the active versus the passive trials. Note that one subject only had an active trial and thus this subject was dropped from

Clinical Neurophysiology, Vol 124, No. 2 (February 2013): pg. 379-390. DOI. This article is @ Elsevier and permission has been granted for this version to appear in e-Publications@Marquette. Elsevier does not grant permission for this article to be further copied/distributed or hosted elsewhere without the express permission from Elsevier. 
the analysis resulting in a total sample size of 9 . In order to account for scaling between subjects, the active and passive data were normalized by the mean peak-to-peak amplitude of the 2 trials for each subject. A paired $t$-test was then done with the level of significance fixed at $p<0.05$.

ii. $\quad$ The difference in the mean power of the central $\beta$ band frequencies $(20-25 \mathrm{~Hz}$ ) in active versus passive trials. For this analysis, only the electrodes over the sensorimotor cortex were considered. Specifically, the sensorimotor areas, consisting of the central row $(\mathrm{C} 3, \mathrm{C} 1, \mathrm{Cz}, \mathrm{C} 2$ and $\mathrm{C} 4)$, the row anterior to the central row (FC3, FC1, FCz, FC2 and FC4) and the row posterior to the central row (CP3, CP1, CPz, CP2 and CP4) were used in the statistical analysis. An ANOVA (Task, Electrode and Task*Electrode as fixed factors and Subject as a random factor) was conducted to identify differences between the active and passive task in regions overlying the sensorimotor cortices. Also, individual paired $t$-tests were performed to identify the individual electrodes with a significant difference between the two tasks. Level of significance was fixed at $p<0.05$ for these tests.

iii. The cross correlation between group average composite EMG waveforms for 5 leg muscles (SOL, MG, TA, MH, RF and VM) and the group average EEG voltage waveform at the $\mathrm{Cz}$ electrode. Separate correlation coefficients $(r)$ and $p$ values (testing hypothesis of no correlation) were calculated for each muscle using the corrcoef function in MATLAB. Level of significance was set at $p<0.05$ for this test.

\section{Results}

The ensemble-averaged EEG waveforms at the Cz electrode for both individual subjects and the group average demonstrated voltage changes throughout the pedaling cycle are shown in Fig. 2. The groupaveraged waveforms at the $\mathrm{Cz}$ electrode for the active and the passive pedaling trials showed alternate positive and negative potentials, occurring twice during the pedaling cycle. The positive peaks ( $P 1$ and P2) occurred around the TDC $+90^{\circ}(25 \%)$ and TDC $+270^{\circ}(75 \%)$ marks of the pedaling cycle. The positive peaks were separated by a negative peak (N1) occurring around the BDC (bottom dead center:

Clinical Neurophysiology, Vol 124, No. 2 (February 2013): pg. 379-390. DOI. This article is (C) Elsevier and permission has been granted for this version to appear in e-Publications@Marquette. Elsevier does not grant permission for this article to be further copied/distributed or hosted elsewhere without the express permission from Elsevier. 
right leg down and left leg up, corresponding to the TDC $+180^{\circ}$ mark $(50 \%))$ of the pedaling cycle. Another negative peak occurred at approximately the TDC position, but this peak was not analyzed further, as resizing of the cycles led to distortions and rejection of data points at the beginning and end of the EEG waveforms corresponding to the TDC position. The peak-to-peak amplitude of the EEG waveform was significantly greater $(p<0.01)$ in passive as compared to active trials (Table 1 ). The passive trials were on average $2.2 \pm 0.9$ (mean \pm standard deviation) times greater than the active trials.

(a)

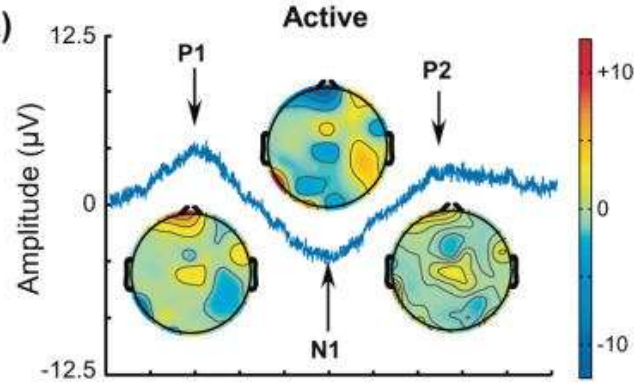

(b)

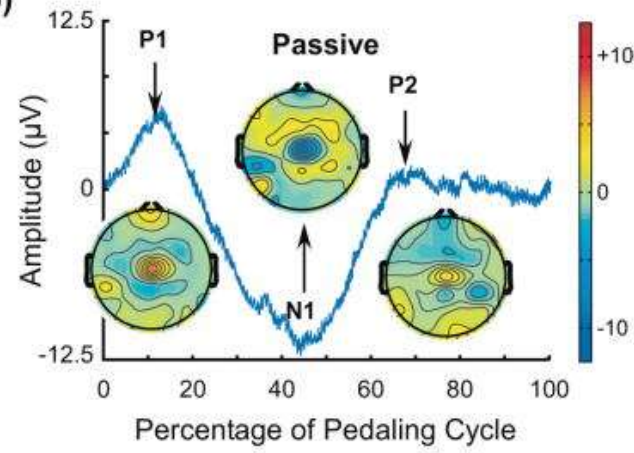

(c)

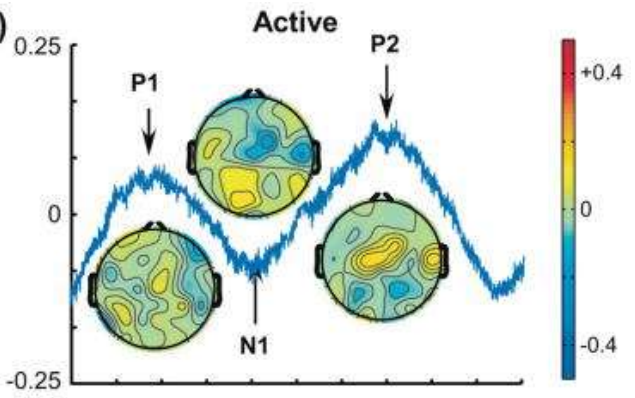

(d)

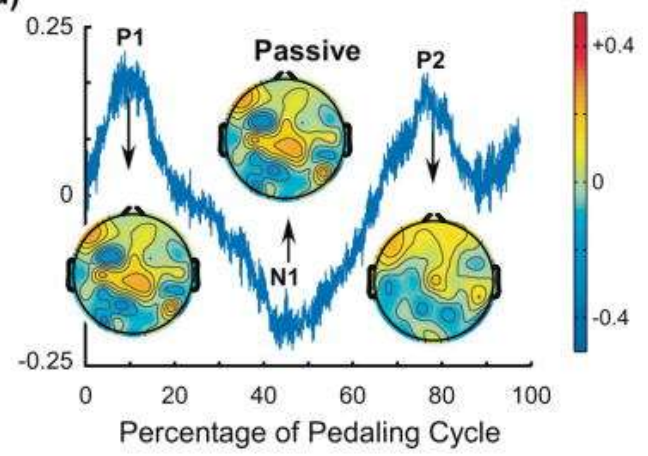

Fig. 2. EEG waveform recorded over the $\mathrm{Cz}$ electrode during pedaling. The arrows indicate the time within the pedaling cycle when the corresponding 2-D topographic maps were generated. In the 2-D maps, the nose is pointing upwards, left and right ears are on the left and right side respectively. Blue indicates relative negativity and red indicates relative positivity. (a) The active pedaling condition for a single subject. (b) The passive pedaling condition for a single subject, in which the researcher turned the crank. (c) The group average active pedaling condition. (d) The group average passive pedaling condition. The 2-D maps were generated using Scan 4.3 (Compumedics Neuroscan). 
NOT THE PUBLISHED VERSION; this is the author's final, peer-reviewed manuscript. The published version may be accessed by following the link in the citation at the bottom of the page.

Table 1 Peak to peak amplitude $(\mu \mathrm{V})$ from ensemble-averaged waveform at the $\mathrm{Cz}$ electrode during active and passive pedaling.

\begin{tabular}{lrr}
\hline Subject & \multicolumn{2}{c}{ Active Passive } \\
\hline 1 & 6.981 & 8.673 \\
2 & 14.766 & 21.729 \\
3 & 3.026 & 7.523 \\
4 & 9.416 & 24.022 \\
5 & 9.158 & 18.836 \\
6 & 1.27 & 2.924 \\
7 & 2.61 & 4.455 \\
8 & 12.174 & 14.536 \\
9 & 14.368 & 59.491 \\
Mean & 8.197 & 18.021 \\
Standard deviation & 5.085 & 17.291 \\
\hline
\end{tabular}

Topography of the voltage distribution at P1 and P2 in ensemble-averaged EEG waveforms showed an area of positive potential (red) over the central scalp areas (please see insets in Fig. 2) in individual subjects as well as in the group average. Similarly, the voltage topography at N1 showed an area of negative potential (blue) over the same area. The areas of positive and negative voltages were better defined in topographic maps derived from group average waveforms than from any of the individual trials. Cortical maps of the distributed source localization, based on the group average at the P1 and P2 time points, resulted in peak current values within the leg somatosensory and motor cortical regions (Fig. 3). This suggested that the areas of voltage change during pedaling were common across all subjects, with preponderant effects over the central electrodes, consistent with the leg representation area of the sensorimotor cortices. 


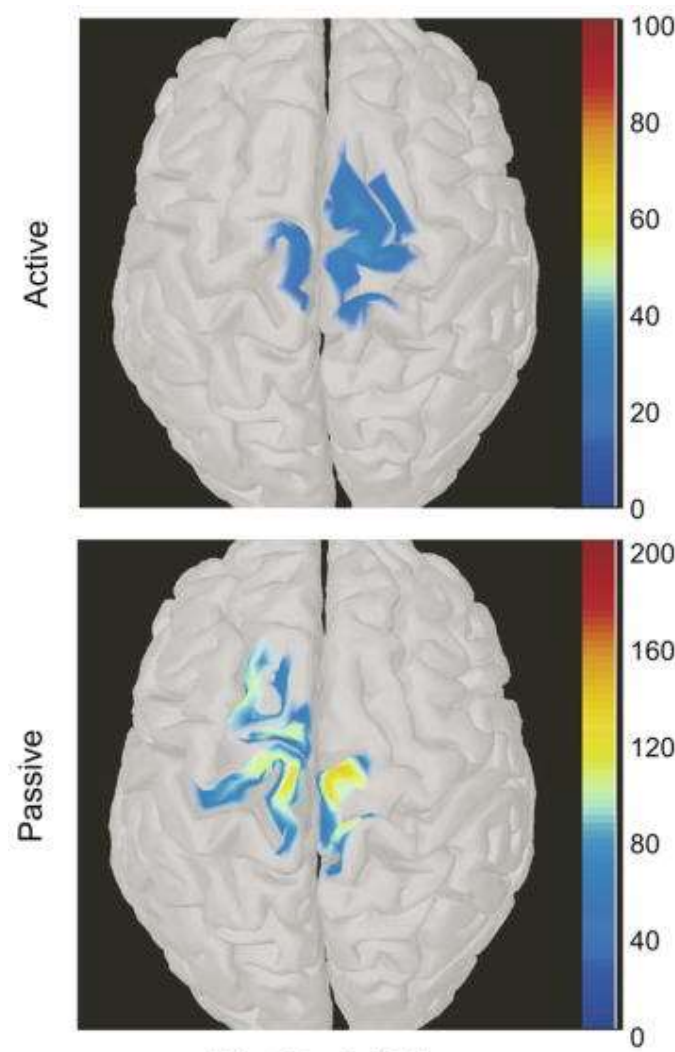

First Peak (P1)
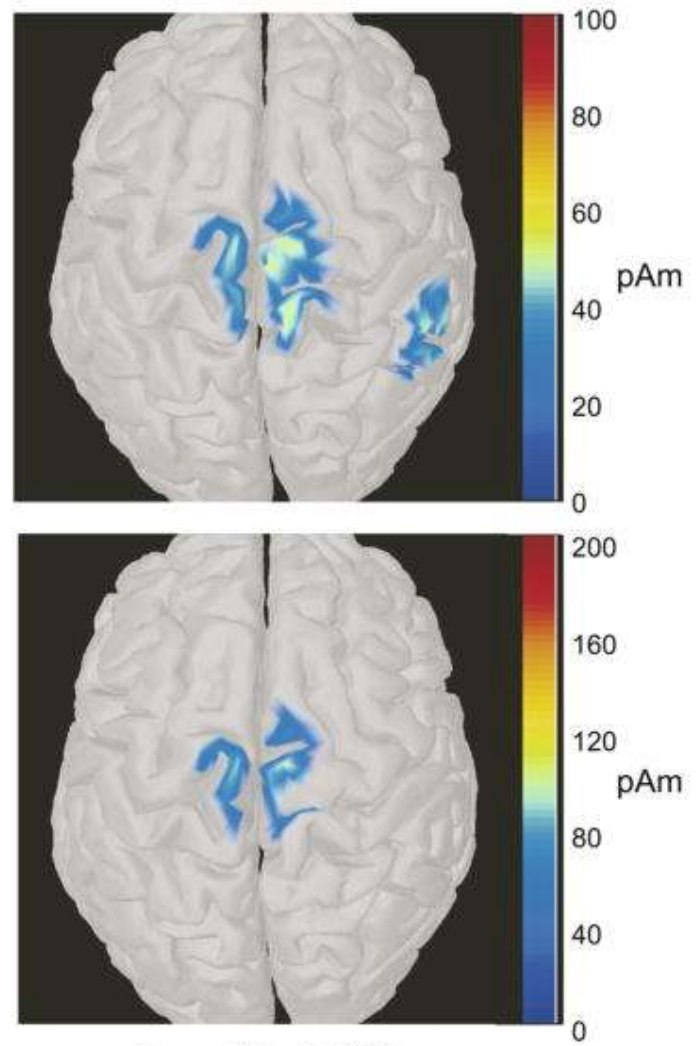

Second Peak (P2)

Fig. 3. Distributed current source maps were calculated at timepoints associated with $\mathrm{P} 1$ and P2 for the group averaged active and passive conditions (See Fig. 2) using Brainstorm software. The calculated current dipole moments are displayed on a standard brain surface. The threshold level for current density was set to display only the regions with the highest current magnitudes (Active P1: 20pAm, Active P2: 25pAm, Passive P1: 70pAm, Passive P2: 60pAm). In all cases, the highest current values were obtained in the regions of the primary somatosensory and motor cortices, consistent with somatotopic regions traditionally associated with the legs.

\section{A significant negative cross-correlation between the group} ensemble-averaged EEG waveform at the $\mathrm{Cz}$ electrode (expected to overlie the leg sensorimotor cortical areas) during active trials and the composite EMG waveforms (as explained above) were observed for the $\mathrm{RF}(r=-0.77, p<0.01)$ the $\mathrm{MH}(r=-0.85, p<0.01)$ and the TA $(r$ $=-0.70, p<0.01$ ) muscles (Fig. 4). Also, the cross correlation coefficient (between the EEG and EMG waveforms) for these muscles was greatest for the electrodes overlying the approximate leg representation area of the sensorimotor cortex (Fig. 4). Composite EMG waveforms for the VM and SOL muscles also had a significant correlation with the EEG waveform at the $\mathrm{Cz}$ electrode $(r=0.25$, and 0.64 respectively, and $p<0.01$ for both), but the correlation was not 
at maximum in the electrodes over the center of the scalp (leg sensorimotor areas) for either of these muscles.

(a)

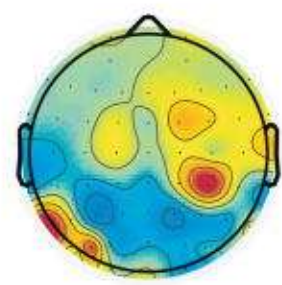

(b)

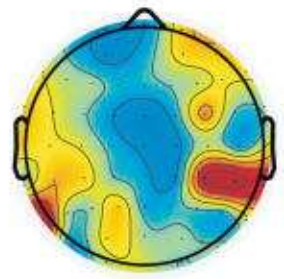

(c)

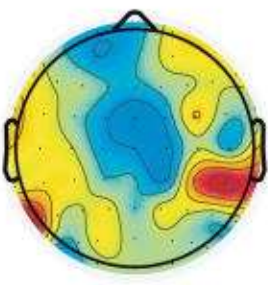

(d)

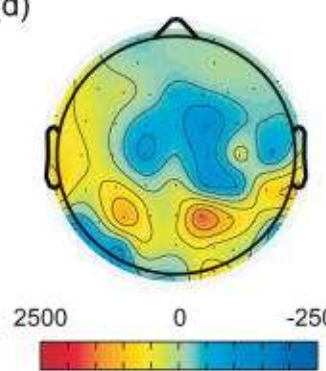

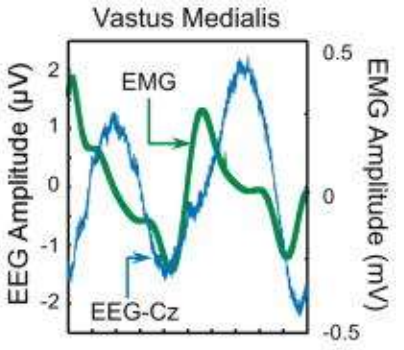
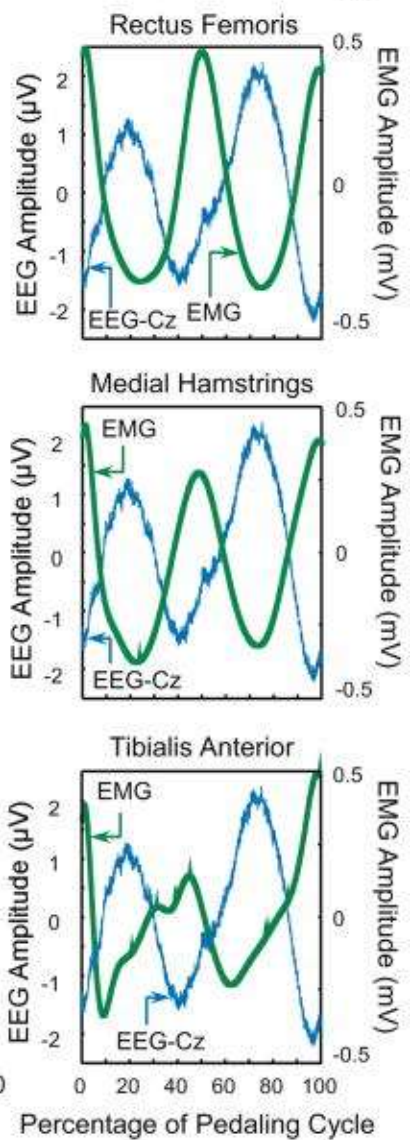

Fig. 4. 2-D topographic maps showing the cross correlation (non-normalized, zero time lag) between the ensemble averaged EEG and the composite EMGs from the VM, $\mathrm{RF}, \mathrm{MH}$ and TA muscles (left panels in figures a-d respectively) during active pedaling. The 2-D maps were created by interpolating the correlation obtained at each of the 64 electrodes over the scalp. These 2-D topographic maps were generated using EEGLAB. The right panels show the EEG waveform at the $\mathrm{Cz}$ electrode and the composite EMGs from the VM, RF, MH and TA muscles.

Desynchrony (i.e. a decrease in power) of the beta band over the center scalp electrodes was observed during both active and 
passive pedaling. A single subject map $\beta$ band power is shown in Fig. 5 , and the group average is shown in Fig. 6. Contrary to our expectation, beta band desynchrony was not focused, but was spread diffusely over the scalp in both the active and the passive conditions. However, group average subtraction maps (active task-passive task) revealed that center beta band power $(20-25 \mathrm{~Hz})$ was significantly lower in the active as compared to the passive trials ( $p$ (Tasks) $<0.01$; $($ Task*Electrodes $)=0.101)$. Also, paired $t$-test results (Table 2 ) revealed significant differences between active and passive conditions for the $\mathrm{C} 1, \mathrm{C} 2$ and $\mathrm{CP} 1$ electrodes $(p<0.05)$. Note that the difference in the frequency amplitudes in active versus passive pedaling was better defined for frequencies near the middle of the $\beta$ band $(21,23$ and $25 \mathrm{~Hz}$ ) than for the 10 and $35 \mathrm{~Hz}$ frequencies, which are shown for comparison (Fig. 6).

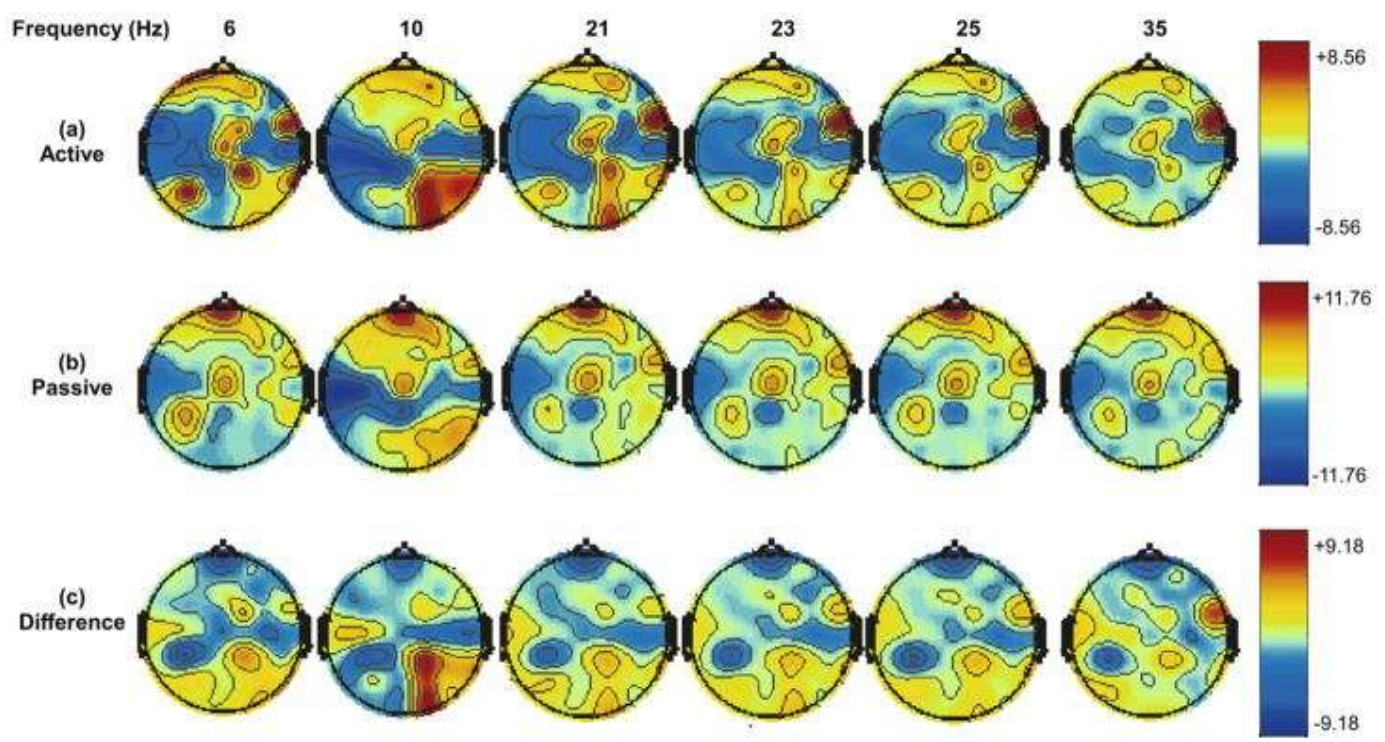

Fig. 5. Topographic map for a single subject at frequencies within the center of the $\beta$ band $(21,23$ and $25 \mathrm{~Hz})$, at the edge of the $\beta$ band $(10$ and $35 \mathrm{~Hz})$ and in the $\beta$ band $(6 \mathrm{~Hz})$. (a) Active pedaling maps are shown. (b) Topographic maps obtained during passive pedaling. (c) The difference in the topographic maps for active and passive pedaling. 
NOT THE PUBLISHED VERSION; this is the author's final, peer-reviewed manuscript. The published version may be accessed by following the link in the citation at the bottom of the page.

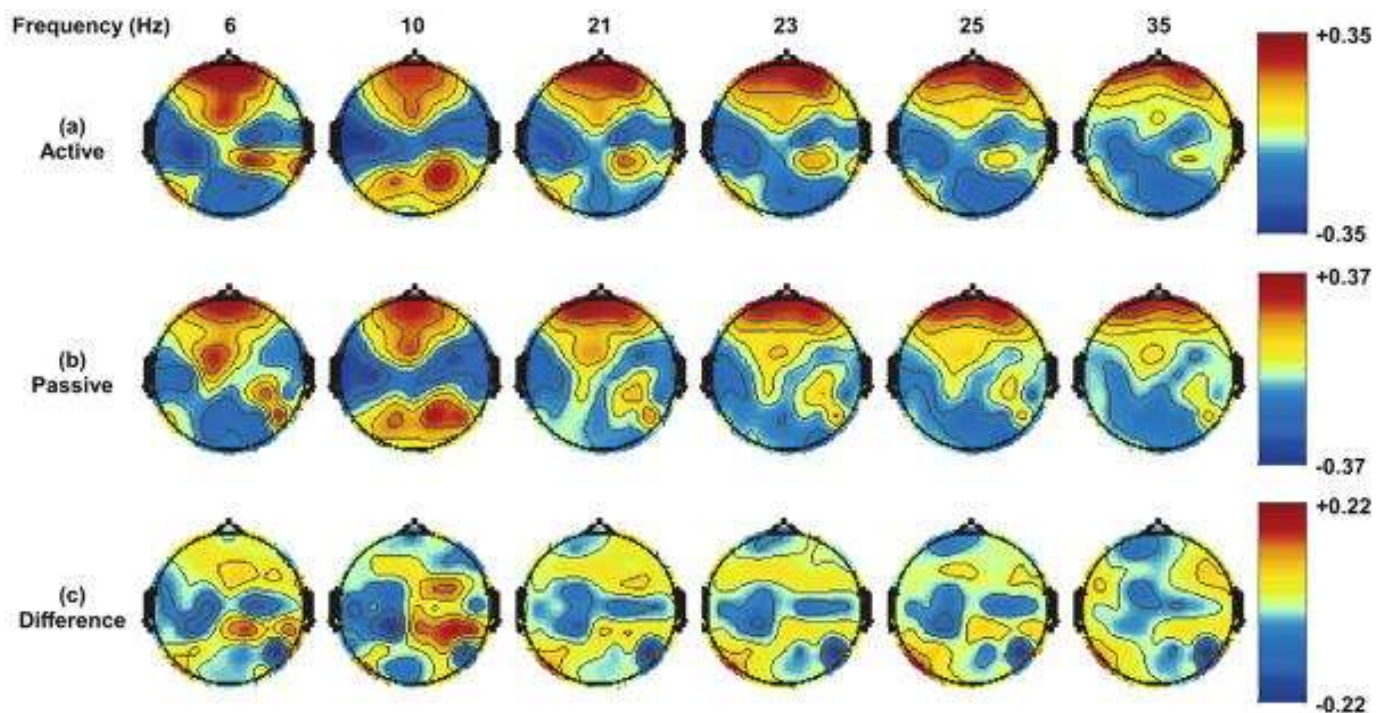

Fig. 6. Group average topographic maps showing the amplitudes at selected frequencies within the center $\beta$ bands $(20-25 \mathrm{~Hz}$ ) during active (a) and passive (b) pedaling. The other frequencies $(6,10$ and $35 \mathrm{~Hz}$ ) are shown for reference. Maps in (c) were obtained by subtracting the passive from the active maps. These group average topographic maps were generated using EEGLAB.

Table 2. ( $p$-value for central electrodes) $p$-values of electrodes lying in the central rows of the cap based on the paired $t$-test.

\begin{tabular}{llllll}
\hline Electrode & $\boldsymbol{p}$-value & Electrode & $\boldsymbol{p}$-value & Electrode & $\boldsymbol{p}$-value \\
\hline FC3 & 0.124 & C3 & 0.80 & CP3 & 0.109 \\
FC1 & 0.203 & C1 & $0.034^{\mathrm{a}}$ & CP1 & $0.005^{\mathrm{a}}$ \\
FCz & 0.938 & Cz & 0.759 & CPz & 0.884 \\
FC2 & 0.959 & C2 & $0.032^{\mathrm{a}}$ & CP2 & 0.169 \\
FC4 & 0.659 & C4 & 0.139 & CP4 & 0.958 \\
\hline
\end{tabular}

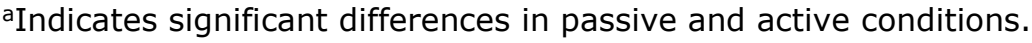

\section{Discussion}

Our results demonstrated the feasibility of using EEG to identify brain electrical activity during a locomotor task (pedaling). Electrical activity recorded using EEG was somatotopically located over the leg representation areas of the sensorimotor cortices (C1, Cz and $C 2)$ and demonstrated a temporal pattern indicating an association with the

Clinical Neurophysiology, Vol 124, No. 2 (February 2013): pg. 379-390. DOI. This article is @ Elsevier and permission has been granted for this version to appear in e-Publications@Marquette. Elsevier does not grant permission for this article to be further copied/distributed or hosted elsewhere without the express permission from Elsevier. 
phase of pedaling. The patterns of EEG signals recorded for the active and the passive trials showed similarity, suggesting predominance of cortical processing of sensory information generated by movement of the lower limbs. However, there were also indications that cortical activity also contributed to motor commands for pedaling. The EEG evidence for motor cortical activity contributions to active pedaling comprised the following: (i) attenuation of the ensemble-averaged EEG voltage during active pedaling, (ii) greater desynchrony (lower power) in $\beta$ band frequencies during active pedaling and (iii) correlation between EEG recorded from the Cz electrode and EMG recorded from "transition muscles" during active pedaling.

\subsection{EEG ensemble-averaged waveform during active and passive pedaling}

The ensemble averaged waveforms recorded at the $\mathrm{Cz}$ electrode during both active and passive pedaling were cyclical in nature, with approximately twice the frequency of the pedaling cycle. The cyclical nature of these slow cortical potentials and the alternating field potentials (Fig. 2) suggests modulation of the brain activity during different phases of the pedaling cycle. These cortical potentials are similar to movement related brain potentials (MRBPs), which are indicative of preparatory and execution stages of a voluntary action (Vaughan et al., 1968). MRBPs are characterized by a negative going waveform that indicates cortical activity during motor tasks (Shibasaki et al., 1980; Barrett et al., 1986). A $\beta$ frequency decrease in power (event related desynchronization), followed by a power increase (event related resynchronization) has been observed with MRBPs for both active and passive foot movements (Müller-Putz et al., 2007), similar to the current active and passive pedaling results. The exact role of the peaks and valleys obtained during the oscillatory ensemble averaged waveform is unclear. The valleys might correspond to the $\beta$ desynchronization associated with muscle drive, while the peaks might correspond to resynchronization; however, his hypothesis requires further investigation.

Clinical Neurophysiology, Vol 124, No. 2 (February 2013): pg. 379-390. DOI. This article is (C) Elsevier and permission has been granted for this version to appear in e-Publications@Marquette. Elsevier does not grant permission for this article to be further copied/distributed or hosted elsewhere without the express permission from Elsevier. 


\subsection{The similarity of passive and active pedaling on EEG signals}

As stated above, the similarity in the EEG waveform recorded at the $\mathrm{Cz}$ electrode during active and passive pedaling suggests that EEG signals during pedaling have a large component dedicated to the processing of afferent information from the lower limbs. Previous research quantifying brain activity during active and passive pedaling using PET has reported similar findings (Christensen et al., 2000). Specifically, there is increased activity in the bilateral primary motor, primary sensory and supplementary motor cortices, during active pedaling as compared to the rest condition. However, activation in identical areas with similar magnitude was also observed during passive pedaling (Christensen et al., 2000). In the current study, activity in the leg representation area of the primary motor cortex associated with active pedaling was apparent only after subtracting the passive activity patterns from the active trials. The magnitude of the ensemble-averaged voltages from the $\mathrm{Cz}$ electrode were also significantly different, with lower voltage fluctuations observed during the active condition.

One explanation for the similarity in the active and passive EEG waveforms is that the subjects might not have fully relaxed during the passive trials. However, EMG recorded during the passive trials did not show any activity, suggesting negligible recruitment of the leg muscles. EMG was not recorded from the trunk or neck muscles and arguably, there could have been efferent corticospinal drive to these muscles for maintenance of trunk balance during passive pedaling. However, this is unlikely to have produced focused voltage changes over the apparent leg representation area of the cortex as evidenced in the topographic maps.

We also considered the possibility that passive trials could have triggered imagined movements with brain signals similar to those associated with active pedaling; however, the localization of the activity in our study suggests that imagined movements were not a substantial contributing factor. The functional neuroanatomy associated with active and imagined movements have been previously documented to be similar (Porro et al., 1996; Deiber et al., 1998;

Clinical Neurophysiology, Vol 124, No. 2 (February 2013): pg. 379-390. DOI. This article is (C) Elsevier and permission has been granted for this version to appear in e-Publications@Marquette. Elsevier does not grant permission for this article to be further copied/distributed or hosted elsewhere without the express permission from Elsevier. 
Stippich et al., 2002; Lacourse et al., 2005). In the current results, it appears unlikely that the activity observed during passive trials was due to imagined movements rather than afferent signals from the limbs. Our results indicated a localization of activity during passive trials that was posterior to the localization during active trials (insets in Fig. 2). In contrast, motor imagery elicits activation in the prefrontal cortices and supplementary motor areas, which lie anterior to the motor cortex (Malouin et al., 2003). This difference in location indicates that the passive pedaling produced EEG signals that were associated almost exclusively with the sensory cues associated with the leg motion.

Since the unperturbed pedaling task is automatic, it may require modest cortical involvement in the active task. Thus, the similarities between the active and passive pedaling are expected to be largely due to the common sensory signals in the active and passive conditions. This masking of the active contributions to the EEG signal suggests that cortical drive might not be a dominant component of the pedaling task, but it still appears to play a role, even in this automatic task.

\subsection{Differences in passive and active condition}

Despite the apparent similarity between the ensemble-averaged EEG waveforms of the active and passive trials, there was a significant difference in the magnitude of the EEG signals generated in the two conditions. The peak-to-peak amplitude of the EEG waveform at the $\mathrm{Cz}$ electrode was smaller in the active as compared to the passive trials. Topographic maps of the ensemble- averaged signals also suggested the possibility of a slight anterior shift in the signals during the active compared to the passive condition (i.e. compare insets in Fig. 2), consistent with an increase in primary motor cortical areas or a decrease in activity within the primary somatosensory cortex during the active task.

We postulate that the attenuation of the ensemble-averaged EEG waveform during active pedaling might have occurred due to centripetal gating of the sensory feedback by the efferent corticospinal output. Gating of sensory input during walking (Duysens et al., 1995; Altenmüller et al., 1995; Brooke et al., 1991a) and pedaling 
(Sakamoto et al., 2004; Brooke et al., 1992) have been previously described. When comparing the somatosensory evoked response to sural nerve stimulation during walking as compared to standing, a $38 \%$ decrease in the P50-N80 complex of the somatosensory evoked potential (SSEP) is observed during walking (Duysens et al., 1995). Further, Altenmüller et al. (1995) demonstrated that the early SSEP components (N40 and N40-P50 complex) are of similar magnitude during walking and standing, while the later SSEP components (P50N80 and N80-P220) show significant attenuation and splitting during walking. These findings have been interpreted as a gating of the sensory input by motor output at the level of the cortex. The spinal cord may also gate sensory feedback, as inhibition in transmission in propriospinal-like neurons at the level of spinal interneurons by corticospinal activity has also been observed during walking (Iglesias et al., 2008). Irrespective of the site of gating, afferent sensory input is inhibited by corticospinal drive; the decreased amplitude of the EEG signal during active pedaling may thus be a marker for corticospinal activity during pedaling.

\subsection{Distribution of the beta band frequency amplitude during active and passive pedaling}

We did not see a focused area of decreased $\beta$ band desynchronization over the leg representation of the sensorimotor cortex in either the active or the passive trials. Akin to the ensembleaveraged voltage waveforms, the frequency amplitude topography was similar in the active and the passive trials (Fig. $6 a$ and b). However, subtraction maps ( $\beta$ band topography during active trials - beta band topography during passive trials) suggest that $\beta$ desynchrony was significantly greater in regions around the leg representation area of the sensorimotor cortices in the active as compared to the passive trials (Fig. 6c). These observations indicate a difference in brain activity during active pedaling, compared to passive movement of the limbs, and implicates the cortex in the control of pedaling movements.

The regions implicated in $\beta$ band desynchronization by the difference in active and passive pedaling were not exactly over the leg representation area of the motor cortex, but lateral to it (Fig. 6). The localization might be associated with generalized activation of the

Clinical Neurophysiology, Vol 124, No. 2 (February 2013): pg. 379-390. DOI. This article is (C) Elsevier and permission has been granted for this version to appear in e-Publications@Marquette. Elsevier does not grant permission for this article to be further copied/distributed or hosted elsewhere without the express permission from Elsevier. 
motor cortex, or with activation of proximal leg muscles. Christensen et al. have also described significant activation in a cortical area between the leg and the shoulder based on PET measurements during pedaling and postulated that this represents motor cortical activity driving the proximal leg muscles (Christensen et al., 2000). Since $\beta$ desynchrony, in general, is a marker for voluntary motor activity, greater $\beta$ desynchrony in the active trials may have been a marker for overall motor cortical activity during pedaling (Jasper and Andrews, 1938; Chatrian et al., 1959; Jasper and Penfield, 1949). Further, most of the motor cortical activity may have been directed towards recruiting proximal leg muscles.

While cortical motor activity is the most likely explanation for the increased $\beta$ band desynchrony during active pedaling, a difference in the sensory signals produced by active and passive pedaling may have contributed to the differences in $\beta$ band power. $\beta$ band desynchrony during times of active motor output is well recognized (Jasper and Andrews, 1938; Chatrian et al., 1959; Jasper and Penfield, 1949); however, there is also an effect of somatosensory feedback on brain oscillations. Brief somatosensory stimuli are followed by increased desynchronization in the $20 \mathrm{~Hz}$ (and $10 \mathrm{~Hz}$ ) oscillations over the bilateral primary sensorimotor cortices, followed by a rebound post-stimulus synchronization in the $20 \mathrm{~Hz}$ oscillations in the contralateral primary sensorimotor cortex and in the supplementary motor area (Jasper and Andrews, 1938; Kuhlman, 1978; Pfurtscheller, 1981; Salmelin and Hari, 1994; Salenius et al., 1997). If the effect of a continuous somatosensory input (as occurs in pedaling) on brain oscillations is similar to that of somatosensory stimulation, increased $\beta$ band desynchrony may well have been the result of an increased sensory input due to voluntary muscle contractions during active pedaling. $\beta$ band desynchrony that is caused by sensory afferents would also explain the similarities of $\beta$ band topography between the active and the passive trials.

\subsection{Correlation between EEG activity and EMG from leg muscles}

The slow varying, ensemble-averaged EEG activity recorded at the $\mathrm{Cz}$ electrode had a strong negative correlation with the composite

Clinical Neurophysiology, Vol 124, No. 2 (February 2013): pg. 379-390. DOI. This article is (C) Elsevier and permission has been granted for this version to appear in e-Publications@Marquette. Elsevier does not grant permission for this article to be further copied/distributed or hosted elsewhere without the express permission from Elsevier. 
(bilateral) EMGs of the RF, MH and TA muscles, which are considered transition muscles of pedaling (Raasch and Zajac, 1999; Neptune et al., 1997). Specifically, the association between EEG and EMG of these three transition muscles suggests involvement of the motor cortex during the relatively challenging task of transitioning between the flexion and extension phases of cycling. There is some evidence that muscles contributing to limb transitions during pedaling may have unique cortical control. For example, in stroke subjects, unilateral pedaling with either the paretic or the non-paretic leg strongly activates the muscles contributing to limb transition (e.g. RF and $\mathrm{MH}$ ) in the stationary leg, while the muscles comprising the plantardorsiflexor functions are only weakly activated under similar conditions (Kautz et al., 2006, 2002). While the effect occurs in both legs, it is more pronounced when subjects pedal with the paretic leg and in subjects with a more severe stroke (Kautz et al., 2006). These observations suggest that corticospinal output that normally inhibits the excitatory intralimb pathways and prevents muscle activity in the stationary leg is lost after stroke (Kautz et al., 2006; Kautz and Patten, 2005). It is important to note that the muscle activities, recorded by EMG, are necessarily coupled with pedaling cycle phase. Thus, the EEG signals might not represent a direct coupling of the cortex to transition muscles. Rather, it is possible that the EEG signals could represent cortical processing involved in the transition phase of pedaling. In either case, the correlation of EEG and EMG of transition muscles (and the transition phases of pedaling) implicates cortical control for the transition phases of cyclical motion.

\subsection{Does the cortex participate in the control of locomotor function in humans?}

There is evidence to suggest that processing of sensory information from the muscles and skin of lower limbs during locomotion occurs at a cortical level, and that cortical motor activity is involved in walking. For example, based on the characteristics of the dorsiflexor stretch reflex responses, brain pathways appear to modulate stretch reflexes during walking (Christensen et al., 2001; Petersen et al., 1998). Similarly, transcranial magnetic stimulation modulates $\mathrm{H}$-reflexes during walking in a phase-dependent manner, supporting the concept of cortical regulation of spinal reflexes during

Clinical Neurophysiology, Vol 124, No. 2 (February 2013): pg. 379-390. DOI. This article is (C) Elsevier and permission has been granted for this version to appear in e-Publications@Marquette. Elsevier does not grant permission for this article to be further copied/distributed or hosted elsewhere without the express permission from Elsevier. 
gait (Christensen et al., 2001; Petersen et al., 1998). Further, it has been shown that the cutaneous reflex response has a transcortical component that is modulated by the phase of gait (Christensen et al., 1999; Nielsen and Sinkjaer, 2002). Recently, EEG patterns have been measured during treadmill stepping using an independent component analysis (ICA) to segregate noise from brain signals. Those results suggest modulation of current sources in several cortical regions including the anterior cingulate, posterior parietal and sensorimotor cortices, across the gait cycle (Gwin et al., 2011). It is unclear, however, how much of the signal can be attributed to sensory feedback and how much is active involvement of the cortex in gait motor commands. Our observations of EEG activity that modulates during pedaling, with significant differences during active and passive pedaling, are consistent with a role for the sensorimotor cortices in the regulation of gait.

While cortical involvement in the motor control of pedaling might have corollaries to cortical control of walking, there remain differences in control of the two tasks. Unlike gait, pedaling is constrained to a circular trajectory, there is minimal need for trunk balance (especially with the semi reclining backboard, as used in this study) and there is no requirement of balancing on a single leg during any phase of pedaling. However, broad similarities in the biomechanics of pedaling and walking and between brain activation during pedaling (Christensen et al., 2000) and immediately after walking (Fukuyama et al., 1997) have been previously described. Therefore, despite the obvious dissimilarities between pedaling and walking, pedaling might serve as a reduced model to study the cortical control of locomotion and its impairment after a neurological injury (Schindler-Ivens et al., 2008, 2004; Kautz et al., 2002, 2006; Kautz and Patten, 2005). As demonstrated in this study, EEG can be used to record brain activity during pedaling and may therefore provide valuable information if applied to these situations.

EMG from neck muscles are a primary concern in measuring EEG signals during walking, and may have contributed noise to the signals in the current study; however, the apparatus used to test EEG during pedaling in the current study appeared to limit neck EMG noise. During walking, neck EMG can contribute substantial noise to EEG signals, resulting in sophisticated techniques for noise removal under

Clinical Neurophysiology, Vol 124, No. 2 (February 2013): pg. 379-390. DOI. This article is @ Elsevier and permission has been granted for this version to appear in e-Publications@Marquette. Elsevier does not grant permission for this article to be further copied/distributed or hosted elsewhere without the express permission from Elsevier. 
these circumstances. For example, EMG noise signal has been reduced using an ICA of current sources in order to identify current sources associated with noise and remove them from the data (Gwin et al., 2010). This approach has been useful in measuring visual-evoked potentials during walking (Gramann et al., 2010) and in identifying current sources associated with walking (Gwin et al., 2011). During pedaling, we found no detectable neck EMG artifacts. Although there is spectral overlap of EEG and EMG signals (e.g. see Goncharova et al., 2003), the EEG electrodes nearest the neck generally had low signal amplitudes and the spectral signature of these electrodes was consistent with EEG, rather than EMG. We attribute the low neck EMG artifacts to the fact that minimal head stabilization was required for the pedaling task. The subject's head rested on a pillow, and subjects were reclined, stationary on a backboard, with a seat to prevent motion of the trunk.

The involvement of the cortex in pedaling has important clinical implications to control of cyclical motor tasks in patients that have had damage to cortical structures or cortical pathways. In stroke survivors, there has been some evidence, based upon infrared imaging of blood flow, that cortical activity during gait is altered after stroke (Miyai et al., 2001, 2003). In addition, there is evidence of cortical reorganization in stroke survivors after treadmill training based on longitudinal fMRI recordings of ankle (Enzinger et al., 2009) or knee (Luft et al., 2008) movements, indirectly implicating the cortex in the control of gait. Our results suggest that the cortex participates in cyclical pattern generation, in addition to potentially providing higher order control in locomotor-type tasks. This is consistent with observations in people with stroke, whose gait patterns are disrupted (Knutsson and Richards, 1979; Mulroy et al., 2003) and ultimately could have implications in interpreting the role of the cortex in restoring gait function.

In summary, this study demonstrates EEG signals that suggest a role of cortical activity in pedaling. However, evidence for motor cortical activity during pedaling could only be ascertained with difficulty, since a substantial amount of brain activity during pedaling appeared to be associated with the processing the sensory information. Correlation of the EMG recorded from the transition muscles and the EEG during pedaling suggested corticospinal control

Clinical Neurophysiology, Vol 124, No. 2 (February 2013): pg. 379-390. DOI. This article is (C) Elsevier and permission has been granted for this version to appear in e-Publications@Marquette. Elsevier does not grant permission for this article to be further copied/distributed or hosted elsewhere without the express permission from Elsevier. 
over the activity of these muscles during locomotion. Thus, transitions from flexion to extension (and vice versa) during walking may be the locomotor function most vulnerable to impairment after an injury to the cortex, as in stroke.

\section{Highlights}

- Pedaling produces slow changes in brain potentials with a frequency of double the pedaling frequency, correlated with transition muscle activity.

- Pedaling results in beta desynchronization in scalp regions associated with motor activities.

- There are differences in brain potentials associated with active and passive pedaling.

\section{References}

Altenmüller E, Berger W, Prokop T, Trippel M, Dietz V. Modulation of sural nerve somatosensory evoked potentials during stance and different phases of the step-cycle. Electroencephalogr Clin Neurophysiol. 1995;96:516-25.

American Clinical Neurophysiology Society. Guideline 5: Guidelines for standard electrode position nomenclature. J Clin Neurophysiol. $2006 ; 23: 107-10$.

Babu RS, Namasivayam A. Recovery of bipedal locomotion in bonnet macaques after spinal cord injury: footprint analysis. Synapse. $2008 ; 62: 432-47$.

Bakker M, De Lange FP, Helmich RC, Scheeringa R, Bloem BR, Toni I. Cerebral correlates of motor imagery of normal and precision gait. Neuroimage. 2008;41:998-1010.

Barrett G, Shibasaki H, Neshige R. Cortical potentials preceding voluntary movement: evidence for three periods of preparation in man. Electroencephalogr Clin Neurophysiol. 1986;63:327-39.

Brooke JD, Collins DF, Boucher S, McIlroy WE. Modulation of human short latency reflexes between standing and walking. Brain Res. $1991 ; 548: 172-8$.

Clinical Neurophysiology, Vol 124, No. 2 (February 2013): pg. 379-390. DOI. This article is (C) Elsevier and permission has been granted for this version to appear in e-Publications@Marquette. Elsevier does not grant permission for this article to be further copied/distributed or hosted elsewhere without the express permission from Elsevier. 
NOT THE PUBLISHED VERSION; this is the author's final, peer-reviewed manuscript. The published version may be accessed by following the link in the citation at the bottom of the page.

Brooke JD, McIlroy WE, Collins DF. Movement features and H-reflex modulation. I. Pedalling versus matched controls. Brain Res. $1992 ; 582: 78-84$.

Chatrian GE, Petersen MC, Lazarte JA. The blocking of the rolandic wicket rhythm and some central changes related to movement. Electroenceph Clin Neurophysiol. 1959;11:497-510.

Christensen LO, Andersen JB, Sinkjaer T, Nielsen J. Transcranial magnetic stimulation and stretch reflexes in the tibialis anterior muscle during human walking. J Physiol. 2001;531:545-57.

Christensen LO, Johannsen P, Sinkjaer T, Petersen N, Pyndt HS, Nielsen JB. Cerebral activation during bicycle movements in man. Exp Brain Res. $2000 ; 135: 66-72$.

Christensen LO, Morita H, Petersen N, Nielsen J. Evidence suggesting that a transcortical reflex pathway contributes to cutaneous reflexes in the tibialis anterior muscle during walking in man. Exp Brain Res. 1999;124:59-68.

Ciccarelli O, Toosy AT, Marsden JF, Wheeler-Kingshott CM, Sahyoun C, Matthews PM, et al. Identifying brain regions for integrative sensorimotor processing with ankle movements. Exp Brain Res. $2005 ; 166: 31-42$.

Courtine G, Roy RR, Raven J, Hodgson J, McKay H, Yang H, et al. Performance of locomotion and foot grasping following a unilateral thoracic corticospinal tract lesion in monkeys (Macaca mulatta) Brain. $2005 ; 128: 2338-58$.

Deiber MP, Ibañez V, Honda M, Sadato N, Raman R, Hallett M. Cerebral processes related to visuomotor imagery and generation of simple finger movements studied with positron emission tomography. Neuroimage. 1998;7:73-85.

Delorme A, Makeig S. EEGLAB: an open source toolbox for analysis of singletrial EEG dynamics including independent component analysis. J Neurosci Methods. 2004;134:9-21.

Deutschlander A, Stephan T, Hufner K, Wagner J, Wiesmann M, Strupp M, et al. Imagined locomotion in the blind: an fMRI study. Neuroimage. 2009;45:122-8.

Clinical Neurophysiology, Vol 124, No. 2 (February 2013): pg. 379-390. DOI. This article is (C) Elsevier and permission has been granted for this version to appear in e-Publications@Marquette. Elsevier does not grant permission for this article to be further copied/distributed or hosted elsewhere without the express permission from Elsevier. 
NOT THE PUBLISHED VERSION; this is the author's final, peer-reviewed manuscript. The published version may be accessed by following the link in the citation at the bottom of the page.

Dobkin B, Barbeau H, Deforge D, Ditunno J, Elashoff R, Apple D, et al. The evolution of walking-related outcomes over the first 12 weeks of rehabilitation for incomplete traumatic spinal cord injury: the multicenter randomized spinal cord injury locomotor trial. Neurorehabil Neural Repair. 2007;21:25-35.

Dobkin BH, Firestine A, West M, Saremi K, Woods R. Ankle dorsiflexion as an fMRI paradigm to assay motor control for walking during rehabilitation. Neuroimage. 2004;23:370-81.

Duysens J, Tax AA, Nawijn S, Berger W, Prokop T, Altenmüller E. Gating of sensation and evoked potentials following foot stimulation during human gait. Exp Brain Res. 1995;105:423-31.

Enzinger C, Dawes H, Johansen-Berg H, Wade D, Bogdanovic M, Collett J, Guy C, Kischka U, Ropele S, Fazekas F, Matthews PM. Brain activity changes associated with treadmill training after stroke. Stroke. 2009;2009(40):2460-7.

Fukuyama $\mathrm{H}$, Ouchi $\mathrm{Y}$, Matsuzaki S, Nagahama $\mathrm{Y}$, Yamauchi $\mathrm{H}$, Ogawa $\mathrm{M}$, et al. Brain functional activity during gait in normal subjects: a SPECT study. Neurosci Lett. 1997;228:183-6.

Goncharova II, McFarland DJ, Vaughan TM, Wolpaw JR. EMG contamination of EEG: spectral and topographical characteristics. Clin Neurophysiol. 2003;114:1580-93.

Gramann K, Gwin JT, Bigdely-Shamlo N, Ferris DP, Makeig S. Visual evoked responses during standing and walking. Front Hum Neurosci. $2010 ; 4: 202$.

Gwin JT, Gramann K, Makeig S, Ferris DP. Removal of movement artifact from high-density EEG recorded during walking and running. J Neurophysiol. 2010;103:3526-34.

Gwin JT, Gramann K, Makeig S, Ferris DP. Electrocortical activity is coupled to gait cycle phase during treadmill walking. Neuroimage. 2011;54:128996.

Iglesias C, Nielsen JB, Marchand-Pauvert V. Corticospinal inhibition of transmission in propriospinal-like neurones during human walking. Eur J Neurosci. 2008;28:1351-61.

Clinical Neurophysiology, Vol 124, No. 2 (February 2013): pg. 379-390. DOI. This article is (C) Elsevier and permission has been granted for this version to appear in e-Publications@Marquette. Elsevier does not grant permission for this article to be further copied/distributed or hosted elsewhere without the express permission from Elsevier. 
NOT THE PUBLISHED VERSION; this is the author's final, peer-reviewed manuscript. The published version may be accessed by following the link in the citation at the bottom of the page.

Iseki K, Hanakawa T, Shinozaki J, Nankaku M, Fukuyama H. Neural mechanisms involved in mental imagery and observation of gait. Neuroimage. 2008;41:1021-31.

Jahanshahi M, Jenkins IH, Brown RG, Marsden CD, Passingham RE, Brooks DJ. Self-initiated versus externally triggered movements. I. An investigation using measurement of regional cerebral blood flow with PET and movement-related potentials in normal and Parkinson's disease subjects. Brain. 1995;118:913-33.

Jasper $\mathrm{H}$, Andrews $\mathrm{H}$. Electro-encephalography III. Normal differentiation of occipital and precentral regions in man. Arch Neurol Psychiatry. 1938;39:96-115.

Jasper $\mathrm{H}$, Penfield $\mathrm{W}$. Electrocorticograms in man: effect of the voluntary movement upon the electrical activity of the precentral gyrus. Arch Psychiatry Z Neurol. 1949;183:163-74.

Kautz SA, Brown DA, Van der Loos HF, Zajac FE. Mutability of bifunctional thigh muscle activity in pedaling due to contralateral leg force generation. J Neurophysiol. 2002;88:1308-17.

Kautz SA, Patten C. Interlimb influences on paretic leg function in poststroke hemiparesis. J Neurophysiol. 2005;93:2460-73.

Kautz SA, Patten C, Neptune RR. Does unilateral pedaling activate a rhythmic locomotor pattern in the nonpedaling leg in post-stroke hemiparesis? J Neurophysiol. 2006;95:3154-63.

Kelly-Hayes M, Beiser A, Kase CS, Scaramucci A, D'Agostino RB, Wolf PA. The influence of gender and age on disability following ischemic stroke: the Framingham study. J Stroke Cerebrovasc Dis. 2003;12:119-26.

Knutsson E, Richards C. Different types of disturbed motor control in gait of hemiparetic patients. Brain. 1979;102:405-30.

KuhIman WN. Functional topography of the human mu rhythm. Electroencephalogr Clin Neurophysiol. 1978;44:83-93.

Lacourse MG, Orr EL, Cramer SC, Cohen MJ. Brain activation during execution and motor imagery of novel and skilled sequential hand movements. Neuroimage. 2005;27:505-19.

Clinical Neurophysiology, Vol 124, No. 2 (February 2013): pg. 379-390. DOI. This article is (C) Elsevier and permission has been granted for this version to appear in e-Publications@Marquette. Elsevier does not grant permission for this article to be further copied/distributed or hosted elsewhere without the express permission from Elsevier. 
NOT THE PUBLISHED VERSION; this is the author's final, peer-reviewed manuscript. The published version may be accessed by following the link in the citation at the bottom of the page.

Lehmann D, Skrandies W. Reference-free identification of components of checkerboard-evoked multichannel potential fields. Electroencephalogr Clin Neurophysiol. 1980;48:609-21.

Little JW, Harris RM, Sohlberg RC. Locomotor recovery following subtotal spinal cord lesions in a rat model. Neurosci Lett. 1988;87:189-94.

Luft AR, Macko RF, Forrester LW, Villagra F, Ivey F, Sorkin JD, Whitall J, McCombe-Waller S, Katzel L, Goldberg AP, Hanley DF. Treadmill exercise activates subcortical neural networks and improves walking after stroke: a randomized controlled trial. Stroke. 2008;39:3341-50.

Lyalka VF, Zelenin PV, Karayannidou A, Orlovsky GN, Grillner S, Deliagina TG. Impairment and recovery of postural control in rabbits with spinal cord lesions. J Neurophysiol. 2005;94:3677-90.

Malouin F, Richards $\mathrm{CL}$, Jackson PL, Dumas F, Doyon J. Brain activations during motor imagery of locomotor-related tasks: a PET study. Hum Brain Mapp. 2003;19:47-62.

Mehta JP, Verber MD, Wieser JA, Schmit BD, Schindler-Ivens SM. A novel technique for examining human brain activity associated with pedaling using fMRI. J Neurosci Methods. 2009;179:230-9.

Miyai I, Tanabe HC, Sase I, Eda H, Oda I, Konishi I, Tsunazawa Y, Suzuki T, Yanagida T, Kubota K. Cortical mapping of gait in humans: a nearinfrared spectroscopic topography study. Neuroimage. 2001;5:118692.

Miyai I, Yagura H, Hatakenaka M, Oda I, Konishi I, Kubota K. Longitudinal optical imaging study for locomotor recovery after stroke. Stroke. $2003 ; 34: 2866-70$.

Müller-Putz GR, Zimmermann D, Graimann B, Nestinger K, Korisek G, Pfurtscheller G. Event-related beta EEG-changes during passive and attempted foot movements in paraplegic patients. Brain Res. 2007;1137:84-91.

Mulroy S, Gronley J, Weiss W, Newsam C, Perry J. Use of cluster analysis for gait pattern classification of patients in the early and late recovery phases following stroke. Gait Posture. 2003;18:114-25.

Clinical Neurophysiology, Vol 124, No. 2 (February 2013): pg. 379-390. DOI. This article is (C) Elsevier and permission has been granted for this version to appear in e-Publications@Marquette. Elsevier does not grant permission for this article to be further copied/distributed or hosted elsewhere without the express permission from Elsevier 
NOT THE PUBLISHED VERSION; this is the author's final, peer-reviewed manuscript. The published version may be accessed by following the link in the citation at the bottom of the page.

Neptune RR, Kautz SA, Hull ML. The effect of pedaling rate on coordination in cycling. J Biomech. 1997;30:1051-8.

Neuroscan C. Edit 4.3 User's Manual. 2003.

Nielsen JB. How we walk: central control of muscle activity during human walking. Neuroscientist. 2003;9:195-204.

Nielsen JB, Sinkjaer T. Afferent feedback in the control of human gait. J Electromyogr Kinesiol. 2002;12:213-7.

Petersen N, Christensen LO, Morita H, Sinkjaer T, Nielsen J. Evidence that a transcortical pathway contributes to stretch reflexes in the tibialis anterior muscle in man. J Physiol (Lond) 1998;512:267-76.

Pfurtscheller G. Central beta rhythm during sensory motor activities in man. Electroenceph Clin Neurophysiol. 1981;51:253-64.

Porro CA, Francescato MP, Cettolo V, Diamond ME, Baraldi P, Zuiani C, et al. Primary motor and sensory cortex activation during motor performance and motor imagery: a functional magnetic resonance imaging study. J Neurosci. 1996;16:7688-98.

Raasch CC, Zajac FE. Locomotor strategy for pedaling: muscle groups and biomechanical functions. J Neurophysiol. 1999;82:515-25.

Rossignol S. Locomotion and its recovery after spinal injury. Curr Opin Neurobiol. 2000;10:708-16.

Rossignol S, Bouyer L, Langlet C, Barthelemy D, Chau C, Giroux N, et al. Determinants of locomotor recovery after spinal injury in the cat. Prog Brain Res. 2004;143:163-72.

Sahyoun C, Floyer-Lea A, Johansen-Berg H, Matthews PM. Towards an understanding of gait control: brain activation during the anticipation, preparation and execution of foot movements. Neuroimage. $2004 ; 21: 568-75$.

Sakamoto M, Nakajima T, Wasaka T, Kida T, Nakata H, Endoh T, et al. Loadand cadence-dependent modulation of somatosensory evoked potentials and Soleus H-reflexes during active leg pedaling in humans. Brain Res. 2004:272-285. 1029.

Clinical Neurophysiology, Vol 124, No. 2 (February 2013): pg. 379-390. DOI. This article is (C) Elsevier and permission has been granted for this version to appear in e-Publications@Marquette. Elsevier does not grant permission for this article to be further copied/distributed or hosted elsewhere without the express permission from Elsevier. 
NOT THE PUBLISHED VERSION; this is the author's final, peer-reviewed manuscript. The published version may be accessed by following the link in the citation at the bottom of the page.

Salenius S, Schnitzler A, Salmelin R, Jousmäki V, Hari R. Modulation of human cortical rolandic rhythms during natural sensorimotor tasks. Neuroimage. 1997;5:221-8.

Salmelin R, Hari R. Spatiotemporal characteristics of sensorimotor neuromagnetic rhythms related to thumb movement. Neuroscience. 1994;60:537-50.

Schindler-Ivens S, Brown DA, Brooke JD. Direction-dependent phasing of locomotor muscle activity is altered post-stroke. J Neurophysiol. 2004;92:2207-16.

Schindler-Ivens S, Brown DA, Lewis GN, Nielsen JB, Ondishko KL, Wieser J. Soleus H-reflex excitability during pedaling post-stroke. Exp Brain Res. $2008 ; 188: 465-74$.

Schmitt D. Insights into the evolution of human bipedalism from experimental studies of humans and other primates. J Exp Biol. 2003;206:1437-48.

Shibasaki H, Barrett G, Halliday E, Halliday AM. Components of the movement-related cortical potential and their scalp topography. Electroencephalogr Clin Neurophysiol. 1980;49:213-26.

Sockol MD, Raichlen DA, Pontzer H. Chimpanzee locomotor energetics and the origin of human bipedalism. Proc Natl Acad Sci USA. 2007;104:122659.

Stippich C, Ochmann H, Sartor K. Somatotopic mapping of the human primary sensorimotor cortex during motor imagery and motor execution by functional magnetic resonance imaging. Neurosci Lett. 2002;331:50-4.

Tadel F, Baillet S, Mosher JC, Pantazis D, Leahy RM. Brainstorm: a userfriendly application for MEG/EEG analysis. Comput Intell Neurosci. 2011;2011:879716.

Vaughan HJ, Costa L, Ritter W. Topography of the human motor potential. Electroencephalogr Clin Neurophysiol. 1968;25:1-10.

Wagner J, Stephan T, Kalla R, Bruckmann H, Strupp M, Brandt T, et al. Mind the bend: cerebral activations associated with mental imagery of walking along a curved path. Exp Brain Res. 2008;191:247-55.

Clinical Neurophysiology, Vol 124, No. 2 (February 2013): pg. 379-390. DOI. This article is (C) Elsevier and permission has been granted for this version to appear in e-Publications@Marquette. Elsevier does not grant permission for this article to be further copied/distributed or hosted elsewhere without the express permission from Elsevier. 
NOT THE PUBLISHED VERSION; this is the author's final, peer-reviewed manuscript. The published version may be accessed by following the link in the citation at the bottom of the page.

Clinical Neurophysiology, Vol 124, No. 2 (February 2013): pg. 379-390. DOI. This article is (C) Elsevier and permission has been granted for this version to appear in e-Publications@Marquette. Elsevier does not grant permission for this article to be further copied/distributed or hosted elsewhere without the express permission from Elsevier. 